\title{
Thermoelectric Power Generation using Waste Heat of Automobile
}

\author{
Shrutika Karpe ${ }^{+*}$ \\ †Mechanical Engineering, Savitribai Phule Pune University, Pune, India \\ Accepted 03 March 2016, Available online 15 March 2016, Special Issue-4 (March 2016)
}

\begin{abstract}
In recent years, global warming and the limitations in use of energy resources increase environmental issues of emissions. Also In industry, most of the expenses are due to energy (both electrical and thermal), labour and materials. But out of them energy would relate to the manageability of the cost or potential cost savings and thus energy management will help in cost reduction. The possibilities of thermoelectric systems' contribution to "green" technologies, specifically for waste heat recovery from industry exhausting flue gases. It results into extensive research on green technologies producing electricity. As waste heat recovering techniques, such as thermoelectric generator (TEG) is developed .Its implementation in automobile industry is carried out in many ways. Previous research shows that TEG as a waste heat harvesting method is useful. Due to distinct benefits of Thermoelectric generators, they have become a promising alternative green technology. Thermoelectric generator direct converts waste-heat energy into electrical power where it is unnecessary to consider the cost of the thermal energy input. The application of this technology can also improve the overall efficiency the of energy conversion systems. Even though output of TEGs are low with available techniques, feasible electricity generation is possible due to waste heat emitted from the automobile (internal combustion engine operation).
\end{abstract}

Keywords: Gasoline engine, waste heat, TEGs, electricity.

\section{Introduction}

\subsection{Field of Invention}

This invention relates to the Internal Combustion Engine. Among all research directions, waste heat recovery (WHR) is most concerned, due to the widespread existence and high accessibility of suitable resources. According to India Bureau of Energy Efficiency, the benefits of WHR includes reduction in the process consumption and costs, reduction in pollution and equipment sizes, and also reduction in auxiliary energy consumption. While there are a number of devices to fulfill WHR, thermoelectric generator (TEG) has been utilized in most automotive applications. A thermoelectric power generator is a solid s device which waste heat energy into electrical energy which works on seebeck effect and peltier effect.

\subsection{Background of Invention}

In recent years, global warming and the limitations in use of energy resources increase environmental issues of emissions. The possibilities of thermoelectric systems' contribution to "green" technologies, specifically for waste heat recovery from industry exhausting flue gases. Vast quantities of waste heat are discharged into the earth's environment much of it at temperatures which are too low to recover using conventional electrical power generators.

The proposed structure is a distributed multisection and multi-stage network. The target is to tackle problems facing the traditional single-stage system and to advance TEG application in automotive settings.

\subsection{Necessity of TEG}

TEGs are solid-state device, which means that they have no moving parts during their operations. Together with features that they produce no noise and involve no harmful agents, they are the most widely adopted devices for waste heat recovery. Useful electricity generation is possible due to the great amount of waste heat emitted from I.C. engine operation. Reduction in the process consumption and reduction in cost, reduction in pollution and equipment size, reduction in auxiliary energy consumption. Development of hybrid engine vehicles (HEV) All this is possible with TEG.

Table 1 Nomenclature

\begin{tabular}{|c|c|}
\hline Symbols & Name of Symbol \\
\hline $\mathrm{T}_{1}=\mathrm{Th}$ & Temperature of hot side $(\mathrm{K})$ \\
\hline
\end{tabular}




\begin{tabular}{|c|c|}
\hline $\mathrm{T}_{2}=\mathrm{Tc}$ & Temperature of cold side $(\mathrm{K})$ \\
\hline $\mathrm{T}$ & Average temperature $(\mathrm{K})$ \\
\hline $\mathrm{E}_{\mathrm{AB}}$ & Electromotive force $(\mathrm{V})$ \\
\hline$U$ & Current density $\left(\mathrm{A} / \mathrm{m}^{3}\right)$ \\
\hline $\mathrm{Z}$ & Figure of merit $(\mu \mathrm{V} / \mathrm{K})$. \\
\hline$P$ & $\begin{array}{c}\text { Seebeck coefficientSeebeck } \\
\text { coefficient }(\mathrm{V} / \mathrm{K})\end{array}$ \\
\hline $\mathrm{S}$ & Compatibility factor $(1 / \mathrm{V})$ \\
\hline$H$ & Efficieny $(\%)$ \\
\hline
\end{tabular}

Table 2 Abbreviations

\begin{tabular}{|c|c|}
\hline TEG & Thermoelectric generator \\
\hline HEV & Hybrid engine vehicles \\
\hline I.C. & Internal Combustion \\
\hline TE & Thermoelectric \\
\hline BTR & Best temperature range. \\
\hline SiGe & Silicon germanium \\
\hline $\mathrm{Bi}_{2} \mathrm{Te}_{3}$ & Bismuth telluride \\
\hline $\mathrm{CoSb}_{3}$ & Cobalt triantimonide \\
\hline PbTe & Lead telluride \\
\hline DNA & Deoxyribo acid \\
\hline PCR & Polymerase chain reaction \\
\hline NOx & $\begin{array}{l}\text { Oxides of nitrogen } \\
(\mathrm{x}=1 \text { or } 2 \text { or } 3)\end{array}$ \\
\hline WHR & Waste heat recovery \\
\hline EGP & Exhaust gas pipe \\
\hline EGR & Exhaust gas recirculator \\
\hline BMW & Bavarian motor works \\
\hline GMC & General motor company \\
\hline GM & General motor \\
\hline AETEG & $\begin{array}{l}\text { Automotive Exhaust Thermoelectric } \\
\text { Generator }\end{array}$ \\
\hline ATEG & $\begin{array}{c}\text { Automotive Thermoelectric } \\
\text { Generator }\end{array}$ \\
\hline
\end{tabular}

\section{Concept}

\subsection{Seebeck Effect}

Seebeck found that if you placed a temperature gradient across the junctions of two dissimilar conductors, electrical current would flow. The effect is shown below in the Fig.2.1

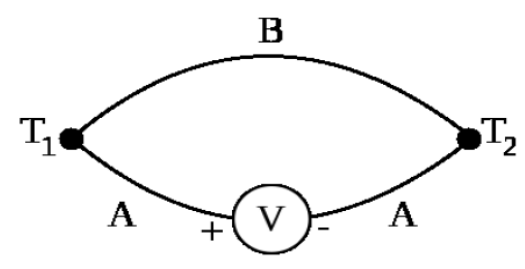

Fig.2.1 Seeback effect

\subsection{Peltier Effect}

Peltier, on the other hand, learned that passing current through two dissimilar electrical conductors, caused heat to be either emitted or absorbed at the junction of the materials. See Fig. 2.2

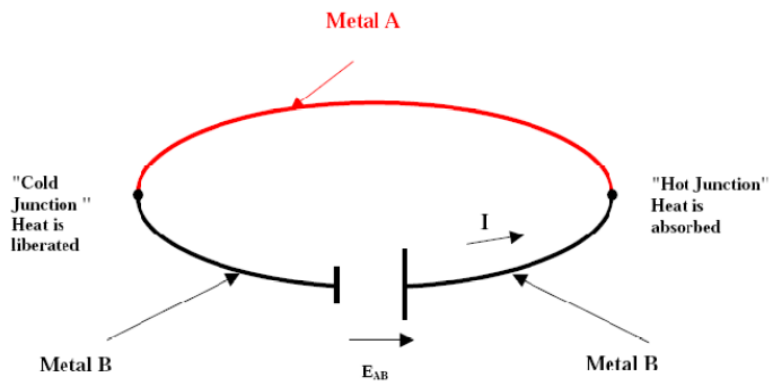

Fig.2.2 Peltier effect

\subsection{Thermoelectric Effect}

The phenomenon involving an inter-conversion of heat and electrical energy may be termed as thermoelectric effect. The effect is shown in Fig.2.3

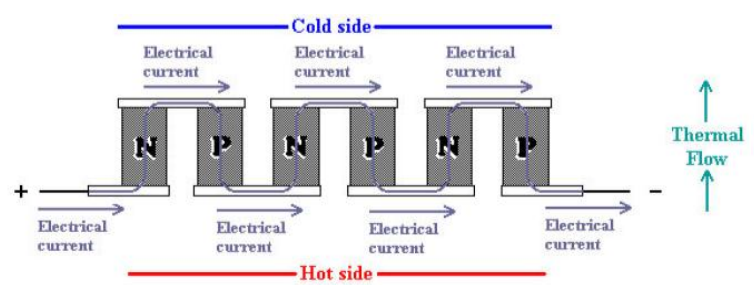

Fig.2.3 Thermoelectric effect

\section{Thermoelectric Generator}

\subsection{Construction}

Thermoelectric generator is a device that converts thermal energy directly into electrical energy.

The TEG structure is "sandwich like", with thermoelectric materials which are "sandwiched" by two heat exchanger plates at its ends respectively. One of the two exchangers is at high temperature, and hence, it is called the hot side of the TEG; while the other side is at lower temperature and is called the cold side of the TEG. There are electrical-insulatethermal-conductive layers between the metal heat exchangers and the TE material of TEG. The two ends of $n$ - and p-type legs are electrically connected by metal .The structure of TEG is as shown in fig.

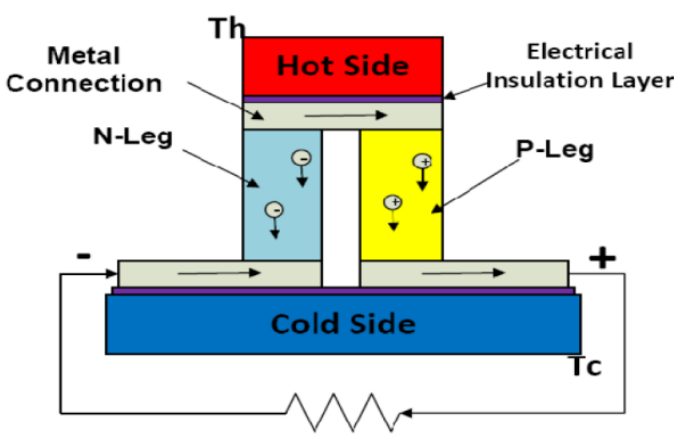

Fig.3.1.1 Simplified illustration of TEGs 


\subsection{Selection of material for TEG}

Metals have been the main materials used in building TEGs, Despite metals' merit of high ratio of electrical to thermal conductivity, modern TE materials includes 26 main semiconductors. The performances of TEGs are largely affected by the materials used. Hence, the selection and combination of TE materials is important for the design of a good TEG. It is necessary to examine and compare the various TE materials. TEGs mainly have segmented structures. Within a segmented structure, each material should be used in their best temperature range (BTR).

Table 3.2.1 N-type material groups by best temperature range

\begin{tabular}{|c|c|c|}
\hline Group & Material & BTR (K) \\
\hline $\begin{array}{c}\text { Hot Side Material } \\
(700 \mathrm{~K}-1000 \mathrm{~K})\end{array}$ & $\begin{array}{c}\mathrm{CoSb} 3 \\
\mathrm{PbTe}\end{array}$ & $\begin{array}{c}650-1100 \\
\mathrm{SiGe}\end{array}$ \\
\hline $\begin{array}{c}\text { Cold Side Material } \\
(300 \mathrm{~K}-400 \mathrm{~K})\end{array}$ & $\mathrm{Bi} 2 \mathrm{Te} 3$ & $<350$ \\
\hline
\end{tabular}

Table 3.2.2P-type material groups by best temperature range

\begin{tabular}{|c|c|c|}
\hline Group & Material & BTR (K) \\
\hline & Zn4Sb3 & $>600$ \\
$\begin{array}{c}\text { Hot Side Material } \\
(700 \mathrm{~K}-1000 \mathrm{~K})\end{array}$ & $\begin{array}{c}\text { CeFe4Sb12 } \\
\text { SiGe }\end{array}$ & $\begin{array}{c}>050 \\
650-1300\end{array}$ \\
& TAGS & 6500 \\
\hline $\begin{array}{c}\text { Cold Side Material } \\
(300 \mathrm{~K}-400 \mathrm{~K})\end{array}$ & $\mathrm{Bi} 2 \mathrm{Te} 3$ & $<450$ \\
\hline
\end{tabular}

\subsection{Segmentation}

In modern TEGs, two or more types of materials are usually used in one leg, to increase the efficiency of the TEG. This approach of increasing TE couple efficiency is called as segmentation. It is a thumb rule that, the compatibility factors of materials within the same leg cannot differ by a factor of 2 or more. If this rule is violated, the maximum efficiency can be decreased by segmentation. Thus, the compatibility factor $s$, is one of the important considerations while selecting TE materials .

\subsection{Compatibility factor}

The value of $u$ which maximizes the reduced efficiency is called as compatibility factor. It is denoted as $S$, and can be expressed as,

$S=\frac{\sqrt{(1+z T)}-1}{\sigma T}$

Where,

Z-Figure of merit $(\mu \mathrm{V} / \mathrm{K})$,
$\mathrm{T}$-average temperature $(\mathrm{T} 2+\mathrm{T} 1) / 2$ in the device $(\mathrm{K})$,

$\sigma$-Seebeck coefficient $(\mathrm{V} / \mathrm{K})$,

u- current density $\left(\mathrm{A} / \mathrm{m}^{3}\right)$,

$S$-Compatibility factor $(1 / \mathrm{V})$

It is clear that $s$ depends on temperature of materials which is derived from other temperature dependent properties like $\sigma, \kappa$, and $\rho$. It means thats cannot be changed with device geometry or the alteration of electrical or thermal currents.

\section{Working}

\subsection{Working Principle}

TEG consists of one hot side and one cold side. The hot side with higher temperature, will drive electrons in the n-type leg toward the cold side with lower temperature, which cross the metallic interconnect, and pass into the p-type leg, thus developing a current through the circuit as sown in Fig.4.1. Holes in the ptype leg will then follow in the direction of the current. The current can then be used to power a load [6].

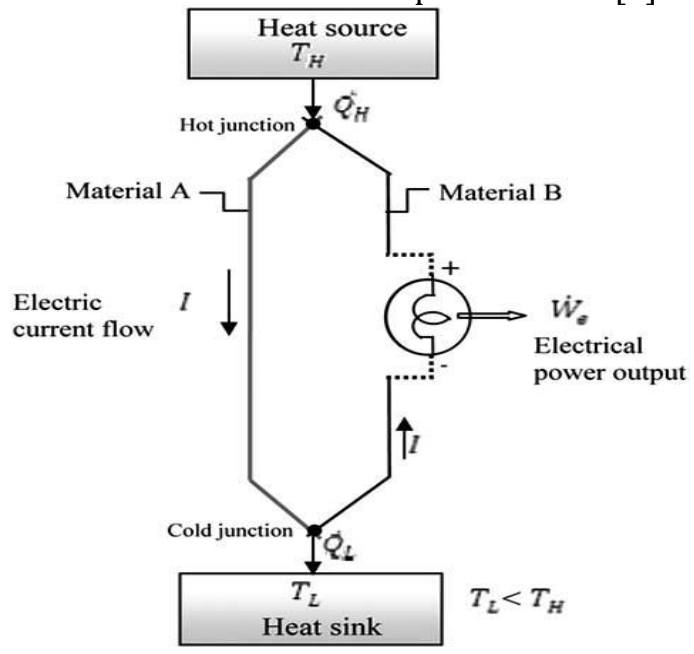

Fig.4.1 Principle of thermoelectric generator

If temperature difference is kept constant, then the diffusion of charge carriers will form a constant heat current, hence a constant electrical current. If the rate of diffusion carriers were equal, there would be no net change in charge within the TE leg.

\subsection{Actual Area of Working}

\section{In Automobile}

The main focus of energy conversion is on three conversion locations mainly exhaust gas pipe (EGP), exhaust gas recirculation (EGR) cooler, and retarder. The most significant factors for the waste heat quality are power density and temperature range.

The EGP is the target of the most automobile waste heat recovery related research. The exhaust system contains a large portion of the total waste heat in vehicle. The gas flow in exhaust gas pipe is relatively 
stable. Fig.4.2.1 shows that TEG utilizing the exhaust gas heat for operation. With exhaust temperatures of $973 \mathrm{~K}$ or more, the temperature difference between exhaust gas on the hot side and coolant on the cold side is close to $373 \mathrm{~K}$.

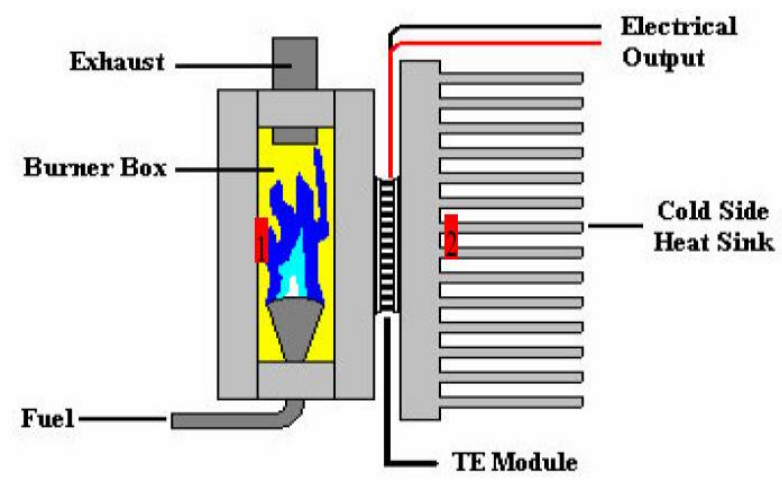

Fig. 4.2.1 TEG utilizing the exhaust gas heat

This temperature difference is capable of generating 100-500W of electricity. In the water coolant based system, though the temperature is lower, it may be high enough to produce significant electricity for use in the vehicle when TEGs are attached.

The main advantage of EGR gas is large temperature difference. Since EGR gas comes directly from the cylinders, its temperature is in the range of $820 \mathrm{~K}-1050 \mathrm{~K}$, which is similar to that in exhaust manifold. Considerable amount of heat. In the power plants and other industries there are lots of flue gases produced having significant amount heat. In thechimneysthetemperatureoffluegaseswouldbearoun d373 Kwhichis the hot junction \& the ambient air is cold junction having temperature $308 \mathrm{~K}$. So there is temperature difference of $353 \mathrm{~K}$. Applying the same technique to this it will gives output of $4.583 \mathrm{mV}$ for one thermocouple loop so by adding these in series in large number we can generate large amount of electricity .

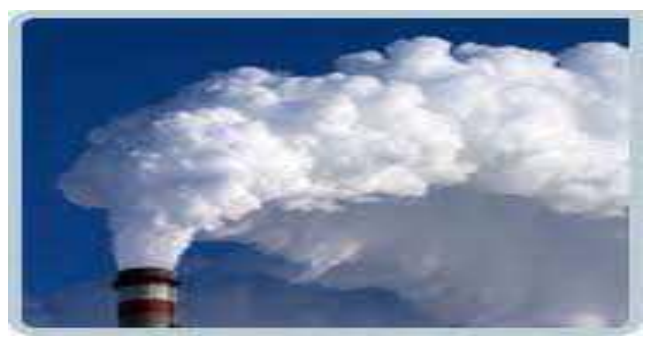

\section{Case Study}

Fig.4.2.2 Flue gases

\section{GMC Sierra Pick-up Truck}

In 2004, the Automobile Exhaust Thermoelectric Generator (AETEG) project waslaunched by Clarkson University and several companies, such as Delphi HarrisonThermal System, GM Power train Division and Hi-Z Technology, Inc. The purpose ofthe project is to perform a feasibility investigation for the application of thermoelectric generators on a GM pick-up truck, as well as to develop a commercial plan for the designed AETEG system.

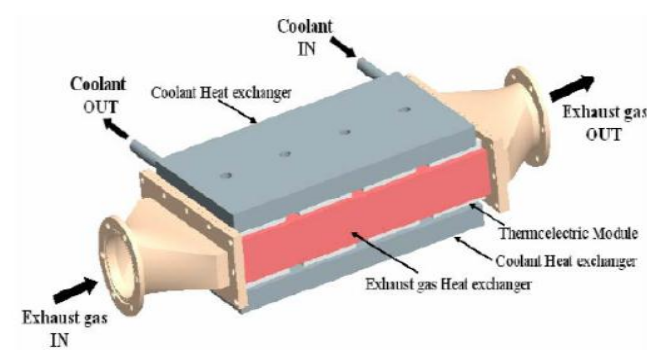

Fig.5.1 The CAD model of the assembled AETEG in GM pick-up truck project.

The device was targeting a power output of $330 \mathrm{~W}$ being supplied with heat from the exhaust and cooled by the conventional coolant circuit. A CAD model of the device can be seen in Fig.5.1. Efficiencies of the electronic device converting the electrically generated TEG saw figures in the order of $80-90 \%$. The maximum amount of electricity created was $140 \mathrm{~W}$ to $225 \mathrm{~W}$ with different types of configurations [6].

\section{BMW Vision Efficient Dynamics Program}

As a world leader in automobile industry, BMW launched its ATEG program Vision Efficient Dynamics in March 2009. The company developed a prototype vehicle (seeFig.5.2) fitted with a thermoelectric generator, based on Bismuth Telluridematerials, for electric power production on board.

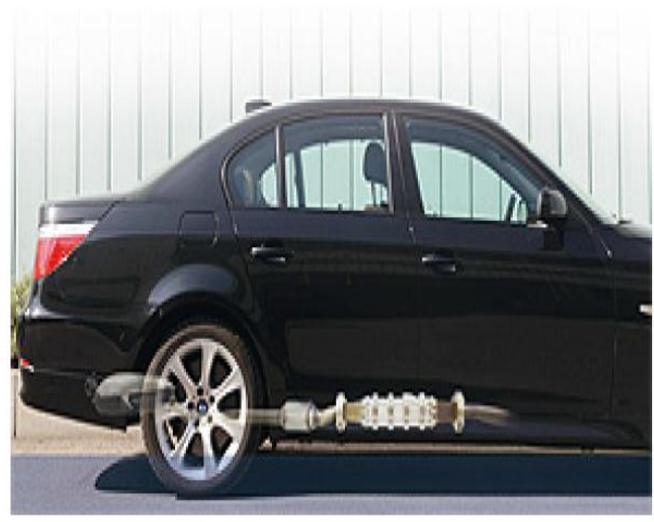

Fig.5.2 BMW prototype vehicle using TEG waste heat recovery

The vehicle involved was BMW 530i. The power production reached levels of 200Wduring highway driving at $130 \mathrm{~km} / \mathrm{h}$. The ZT-value was claimed to be around 0.4.However, there exist better materials already which yield a higher ZT-value, e.g. aPbTesynthesis. Based on tests and observations, BMW 
predict potential fuel consumption savings in the order of $1-8 \%$ depending on driving condition. BMW claims future progress mainly depends on how well the laboratory demonstrated materials find their way to the commercial market.

\section{Benefits}

TEGs are solid-state device, which means that they have no moving parts during their operations. No moving parts so maintenance required is less frequently, no chlorofluorocarbons. Temperature control to within fractions of a degree can be maintained, flexible shape, very small size.

TEGs can be used in environments that are smaller or more severe than conventional refrigeration. TEG has long life, and also it can be controllable by changing the input voltage/current.

\section{Application}

As discussed in section 4.2.1 TEGs are used to develop electricity from waste heat released from EGP due to combustion of fuel and from power plants and some industries due to flue gases from chimneys.

\section{Other applications of TEGs}

Camping, portable coolers, cooling electronic components and small instruments. A camping/car type electric cooler can typically reduce the temperature by up to $20^{\circ} \mathrm{C}\left(36^{\circ} \mathrm{F}\right)$ below the ambient temperature. The cooling effect of Peltier heat pumps can also be used to extract water from the air in dehumidifiers. Climate-controlled jackets, wine coolers, thermal cyclers, satellites and spacecraft. Used for the synthesis of DNA by polymerase chain reaction (PCR).

\section{Discussion}

Waste heat recovery entails capturing and reusing the waste heat from internal combustion engine and using it for heating or generating mechanical or electrical work. It would also help to recognize the improvement in performance and emissions of the engine if these technologies were adopted by the automotive manufacturers.

By using this thermoelectric system one can generate electricity from the high temperature difference and it is available at low cost. In heavy duty vehicles the smoke coming out of the exhaustion system will form the NOxgases which are major concern for the green house gases. But because of this the temperature will come down of exhaust gases so, the formation of the NOx gases will be minimal.

If this concept of thermoelectric system is taken to the nano level or micro level then there will be ample amount of electricity can be generated which are just wasted into the atmosphere.

\section{References}

Jaydeep. V. Joshi1 and N. M. Patel (2012), Thermoelectric system to generate electricity from waste heat of the flue gases, Advances in Applied Science Research, 3 (2):1077-1084

G. Jeffrey Snyder and Tristan S. Ursell (2003), Thermoelectric Efficiency and Compatibility, Physical Review Letters 3 October 2003

Basel I. Ismail, Wael H. Ahmed (2009), Thermoelectric Power Generation Using Waste heat as an Alternative Green Technology, Recent Patents on Electrical Engineering, 2, 2739

Adavbiele A.S. (2013), Generation of Electricity from Gasoline Engine Waste Heat, Journal of Energy Technologies and Policy, Vol.3, No.5

Peltier application notes 20050 SW 112th Ave. Tualatin, Oregon 97062

KTH Information and Communication Technology, Thermoelectric-Generator-Based DCDC Conversion Network for Automotive Applications. Master of Science Thesis Stockholm, Sweden 2011.Trita-ICT-EX-2011:58.Molanli 